\title{
EDITORIAL
}

\section{DESARROLLO DEL PENSAMIENTO CRÍTICO EN LA FORMACIÓN DEL PROFESIONAL ENFERMERO}

\author{
DEVELOPMENT OF CRITICAL THINKING IN THE TRAINING \\ OF THE PROFESSIONAL NURSE
}

\author{
Ingrid Demandes Wolf, Magíster en Enfermería \\ PhD Alicia Infante Peñafiel
}

\section{Escuela de Enfermería Universidad Mayor, Chile}

E-mail: ingrid.demandes@umayor.cl; alicia.infante@umayor.cl

La salud y la educación están sujetas a cambios permanentes que deben dar respuestas a los procesos de globalización e internacionalización, así como también a una sociedad que debe transformarse para responder a indicadores de calidad exigidos en las distintas instituciones del rubro. Lo anterior conlleva a replantear la actividad docente y su profesionalización en el área de salud, con el fin de dar respuesta a los nuevos retos y posicionar al futuro profesional en un rol activo, creativo, reflexivo y crítico, esencial para una práctica de enfermería segura, competente y experta (1).

La educación tradicional no da respuestas a las necesidades del quehacer profesional sanitario actual, por tanto, es indispensable incorporar metodologías de enseñanza y aprendizaje en la formación del profesional enfermero que permita desarrollar la competencia del pensamiento crítico (P.C.). El pensamiento crítico se define "como un nivel más elevado o comprensivo de reflexión; es autorreflexión o autoconciencia: Es el pensamiento que se vuelve sobre sí mismo para examinarse en su coherencia, fundamentación o sustantividad, origen contextual e intereses y valores a los que sirve" (2).

El pensar críticamente involucra razón, honestidad intelectual, amplitud mental en contraposición a lo emocional, a la pereza intelectual y a la estrechez mental, es decir, seguir el hilo de las evidencias, tener en cuenta todas las posibilidades, dejar de lado las emociones, ser precisos, considerar los distintos puntos de vista y explicaciones, sopesar los efectos de las posibles motivaciones y prejuicios, estar interesados en encontrar la verdad más que en tener la razón, estar conscientes 
de nuestros sesgos y prejuicios para impedir que influyan en nuestros juicios (3). Por lo anterior, es relevante insertar el P.C. en la educación superior en enfermería (2) ya que se necesita profesionales que se mantengan informados y sean capaces de evaluar la credibilidad de las fuentes de información, valorar la calidad de un argumento, elaborar un punto de vista propio sobre un tema de la profesión y la disciplina, formular conclusiones claras y pertinentes (4).

Actualmente los perfiles de egresos de las escuelas de Enfermería apuntan a obtener profesionales creativos, autónomos y con pensamiento crítico, debido a esto, es imprescindible que los métodos de enseñanzas y aprendizaje sean acordes a los logros deseados, en contraposición a los métodos de enseñanza tradicional basados en clases magistrales o conferencias que son cuestionados para el desarrollo del P.C., por el escaso aporte al aprendizaje profundo, por la restringida aplicación e integración del conocimiento que entrega a los estudiantes $(5,6)$, lo que dificulta la resolución de problemas que se presentan diariamente en el quehacer profesional y disciplinar (7).

Para desarrollo del P.C. es fundamental contar con docentes creativos, capaces de utilizar métodos de enseñanza, aprendizaje y de evaluación que potencien este tipo de pensamiento, esencial para la toma de decisiones clínicas que contribuyan a mejorar la calidad de la atención (8). Para esto, es vital que los docentes adopten nuevas estrategias que favorezcan el análisis crítico donde el estudiante pueda pensar y desarrollar el saber hacer y ser en el desempeño del rol con racionalidad y autonomía profesional (9). Esto implica potenciar en el currículum académico las habilidades cognitivas por sobre las habilidades psicomotoras; en conjunto con las destrezas comunicacionales e indagativas (10).

En la formación de pregrado el desarrollo del P.C. se puede favorecer, a través de prácticas reflexivas (11), entendiendo estas como una metodología para desarrollar hábitos y destrezas de reflexión en los estudiantes, que promuevan un quehacer pertinente y competente para dar respuestas a situaciones complejas, colaborando a la generación de conocimiento por medio de la investigación, no solo en el ámbito clínico, sino también en el desarrollo teórico disciplinar (12).

El pensamiento crítico contribuye a la formación en el área de la investigación en los estudiantes, a través del desarrollo de una actitud de disposición para hacer consciente los problemas que surgen en la experiencia clínica que sean susceptibles de ser resueltos (13), permitiendo al estudiante esclarecer la información, otorgar un significado y enfocarse en los problemas desde un punto de vista crítico, y de esta forma afrontar temas relevantes por medio de procesos sistemáticos que desarrollen el conocimiento científico (14) de la disciplina y profesión de enfermería. Finalmente, se puede afirmar que el desarrollo del P.C. tiene un impacto en la calidad de los cuidados, junto con otorgar la máxima eficacia en los distintos roles de su quehacer profesional y adquirir autonomía intelectual que permita responder 
a las exigencias que la realidad actual demanda a los profesionales de enfermería (15).

\section{REFERENCIAS}

1. Becerril LC, Rojas AM, Gómez BA, García ML. Importancia del pensamiento reflexivo y crítico en enfermería. Rev Enfer Cardiol. 2015; 23(1): 35-41.

2. Altuve J. El pensamiento crítico y su inserción en la educación superior. Actualidad Contable Faces. 2010; 13(20): 5-18.

3. Gutiérrez CF. Una reflexión interdisciplinar sobre el pensamiento crítico. Revista Latinoamericana de Estudios Educativos. 2013; 9(2): 11-39.

4. De Suárez MJV, Morán HF. Desarrollo del pensamiento crítico en estudiantes de educación superior en El Salvador. Revista Panorama. 2013; 6(10): 7-20.

5. Fasce E. Aprendizaje profundo y superficial. Rev Educ Cienc Salud [Internet]. 2007; [citado 27 ago 2017]; 4(1): 7-8. Disponible en: http://www.udec.cl/ofem/ recs/anteriores/vol412007/RECS4107.pdf\#page $=7$

6. Püschel VAA. A mudança curricular do bacharelado em enfermagem da Escola de Enfermagem da USP: análise documental e vivência dos participantes [Tesis doctoral en Internet]: Sao Paulo: Escola de Enfermagem da Universidad de Sao Paulo. 2011; [citado 27 ago 2017]. 269 p. Disponible en: http://www.teses.usp. br/teses/disponiveis/livredocencia/7/tde-03072014-093555/en.php

7. Price MSM. Cómo desarrollar los procesos del pensamiento crítico mediante la pedagogía de la pregunta. Actualidades pedagógicas. 2012; 59(1): 119-146.

8. Huang YC, Chen HH, Yeh ML, Chung YC. Case studies combined with or without concept maps improve critical thinking in hospital-based nurses: A randomized-controlled trial. Int J Nurs Stud. 2012; 49(6): 747-754.

9. Guzmán JC. La calidad de la enseñanza en educación superior ¿Qué es una buena enseñanza en este nivel educativo? Perfiles educativos. 2011; 33(spe): 129-141.

10. Cardenas L, Bardallo MD, Jiménez MA, Araujo V, Monroy A, López J. Presencia del pensamiento reflexivo y crítico en los currículos de Enfermería en Iberoamérica: Una visión cualitativa. Atas CIAIQ 2016 Investigación Cualitativa en Educación [Internet].2016 [citado 27 ago 2017]; 1: 128-137. Disponible en: http://proceedings.ciaiq.org/index.php/ciaiq2016/article/view/596/585 
11. Pereira-Mendes A. La práctica reflexiva en el aprendizaje clínico: Beneficio para la construcción del pensamiento en enfermería. Revista Electrónica Educare [Internet]. 2016 [citado 27 ago 2017]; 20(1): 1-23. Disponible en: http:// www.revistas.una.ac.cr/index.php/EDUCARE/article/view/7528

12. Moreno I, Siles J. Pensamiento crítico en enfermería: de la racionalidad técnica a la práctica reflexiva. Aquichan [Internet]. 2015 [citado 27 ago 2017]; 14(4): 594-604. Disponible en: http://aquichan.unisabana.edu.co/index.php/ aquichan/article/view/2734

13. Carbogim Fda C, Oliveira LB, Püschel VA. Pensamiento crítico: análisis del concepto bajo la óptica evolucionista de Rodgers. Rev Lat Am Enfermagem [Internet]. 2016 [citado 16 ago 2017]; 24: e2785. Disponible en: http://www.scielo. br/scielo.php?script=sci_arttext\&pid=S0104-11692016000100407\&lng=es

14. Pérez M, Zumba RM, Aguilar JA, Pensamiento crítico aplicado a la investigación científica. Revista Atlante: Cuadernos de Educación y Desarrollo [Internet]. 2017 [citado 26 ago 2017]; 2: 1-10. Disponible en: http://www.eumed. net/rev/atlante/2017/02/investigacion.html

15. Aymes GL. Pensamiento crítico en el aula. Docencia e Investigación [Internet]. 2012 [citado 26 ago 2017]; 22: 41-60. Disponible en: https://ruidera.uclm.es/ xmlui/handle/10578/9053 